Zeitschrift für vergleichende Physiologie 46, 515—540 (1963)

The Bermuda Biological Station, Bermuda, and Department of Zoology,

The University of Michigan, Ann Arbor

\title{
AN EFFECT OF EYESTALK ABLATION ON ANTENNULAR FUNCTION IN THE SPINY LOBSTER, PANULIRUS ARGUS*
}

\author{
By \\ Donald M. Maynard and Hugri Dingle** \\ With 6 Figures in the Text \\ (Received March 6, 1963)
}

\section{Introduction}

A major portion of the brain or supraesophageal ganglia of many decapod Crustacea is located in the eyestalks. In addition to the three optic ganglia - lamina ganglionaris, medulla externa, and medulla interna - each eyestalk also contains the medulla terminalis, a structure often considered to be a lateral extension of the protocerebrum and to contain regions homologous with the mushroom bodies or corpora pedunculata of insects (VIALLANES 1884, 1893; HANSTröm 1925, 1928). Major tracts connect the medulla terminalis with the olfactory centers of the deutocerebrum and with other areas of the brain. On the basis of structural complexity and central connectivity, therefore, the eyestalk ganglia, particularly the medulla terminalis, appear suited for extensive roles in central neural integration.

This suggestion has been strengthened by recent electrophysiological analyses of impulse traffic in the optic peduncles (WIERSMA 1962). Not only is there an afferent flow of complexly coded homolateral visual messages, there is a similarly complex efferent barrage of impulses originating both in the opposite eyestalk and elsewhere in the nervous system. A number of sensory modalities or peripheral locations may be represented. The full significance of such activity for the integrated behavior of the animal is not clear, however. Although ablation of one eyestalk is known to affect both the dynamic and static aspects of posture and equilibrium, these effects usually have been ascribed to simple loss of symmetrical visual stimulation (see ScHöNE 1961). General activity levels are also affected by eyestalk ablation, but these are associated with sensory deprivation and/or interference with the neuroendocrine system of the eyestalks (BLISs 1962). It is therefore of some

* Contribution number 333 from the Bermuda Biological Station for Research, Ine. This work was supported by USPHS Grant NB-03271.

** Present address: Entomological Field Station, Cambridge, England. 
interest to demonstrate that eyestalk removal can interfere specifically with the higher integrative functions of a non-visual system.

This paper presents evidence suggesting that the initiation of foodseeking and feeding activity by chemo-tactile stimulation of an antennular flagellum is disturbed by ablation of the homolateral eyestalk. The disturbance is not generalized; spontaneous movements and reflex withdrawal of the antennule upon stimulation seem unaffected, and antennular cleaning reflexes remain. Normal feeding activity can also be initiated via the other antennule.

\section{Materials and methods}

Twenty-six adult Panulirus argus were used in this study. They were of both sexes and ranged in carapace length from 8,2 to $11,7 \mathrm{~cm}$ or approximately 470 to 1320 gms. Animals were maintained in running sea water in large holding tanks

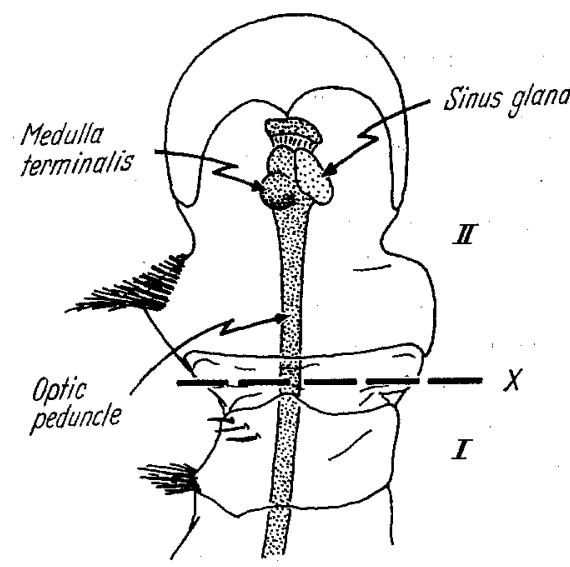

Fig. 1. Dorsal aspect of right eyestalk. $I$, basal segment; $I I$, terminal segment; $X$, point of amputation. All eyestalk ganglia are far distal to the point of eyestalk removal and the remaining central stump of the optic peduncle is several $\mathrm{mm}$ long. Both partial removal of eyestalk ganglia and unintended injury to the remaining central ganglia are therefore unlikely at the Bermuda Biological Station. Individuals were isolated and placed in smaller, glass-fronted aquaria for observation. Various kinds of fresh or frozen fish were normally fed the animals in the holding tanks $2-4$ times per week but intervals between feeding were occasionally prolonged for specimens scheduled for observation.

Eyestalks were amputated at the joint between basal and terminal segments (Fig. 1) and the stump was crushed to reduce bleeding. Mortality was nil.

A clean glass rod was generally used for mechanical stimulation. In some instances a small cloth or paper swab was tied to the end. For chemotactile stimulation the swab was dipped in fish juice - 15-20 gms of fresh or frozen anchovy macerated in $400 \mathrm{~cm}^{3}$ of sea water - immediately before application. In preliminary experiments fish juice was applied directly to the appropriate organ via pipette, but stimulus localization and intensity control proved difficult. When the soaked swab was used, behavioral tests suggest that diffusion and convection of the fish juice was more restricted. For the first few seconds after introduction of the swab into the aquarium, significant concentrations of the stimulating substances seem limited to the immediate region of the swab or to the water through which it has passed.

No particular attempts were made to control or measure the absolute intensity of the chemical stimulus. Within a given series of experiments on a single animal, however, standard procedures of stimulus presentation were used so stimulus intensities were probably comparable.

Most observations were made during the latter half of August, 1962. At that time water temperatures were in the neighborhood of $28^{\circ} \mathrm{C}$. 


\section{Results}

\section{Normal behavior}

Spontaneous aetivity. When undisturbed in the Iaboratory, Panulirus argus spends much of its time during the day either crouched in a corner or other sheltered location, or slowly patrolling the confines of the tank. During this time, one or both of the antennules are in almost continual motion. Such antennular activity increases when foreign objects are presented to the lobster, and was undoubtedly greater in the relatively unfamiliar test aquaria than in the holding tanks.
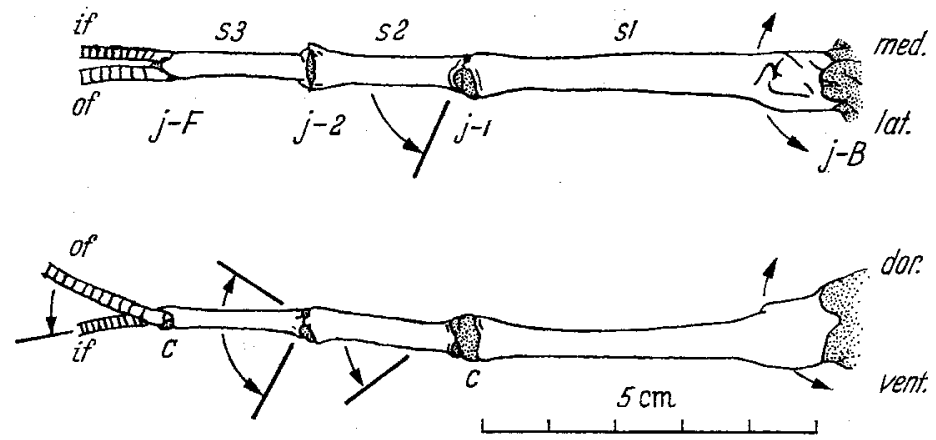

Fig. 2. Basal segments of left antennule. Upper figure, dorsal aspect; lower figure, lateral aspect; flagella cut off about $1 \mathrm{~cm}$ from base, they are typically as long or longer than the entire portion figured (see Fig. 4). Arrows indicate direction and extent of joint movement at $j-1, j-2$, and $j-F$; direction of movement only at $j-B . j-B$, basal joint; $j-1$, first joint; $j-2$, second joint; $j-F$, flagellar or third joint; $s 1$, basal or first segment; $s 2$, second segment; s3, third segment; if, inner flagellum; of, outer flagellum; $c$, elastic cushion. Elastic or pliable cuticle at joints is stippled

Flagellar flicking. The most obvious component of spontaneous antennular activity is a periodic series of flicks of the outer terminal antennular flagellum. Flick rates during a series are characteristically greater than one per second. The basic rates presumably depend upon both body size and environmental temperature.

Each complete flick consists of a rapid, active downward stroke of the outer flagellum followed by a somewhat slower, passive return upward. The downward movement is caused by the contraction of a single depressor muscle (Musculus reductor ${ }_{4}$; SCHMidt 1915; Cochran 1935) which acts against an elastic cushion at the flagellar joint (Fig. 2). At rest, or when the depressor muscle is fully relaxed, the outer flagellum assumes an upward angle of several degrees with the third antennular segment. The inner flagellum has no independent movement; it extends forward from the third segment.

Although flagellar flicking may occur without other antennular movement, it usually is associated with movements of the more proximal 
segments. These often follow one of two characteristic, repeating patterns: the vertical sequence and the horizontal sequence.

Vertical sequence. A typical vertical sequence begins with the basal and second segments pointing forward, and the third segment elevated. The outer flagellum then flicks two or three times and this is followed or accompanied by a depression of the third segment. Subsequent elevation of the third segment completes the cycle. The two proximal segments are thus usually motionless during the sequence. Presumably both extensor and flexor muscles of the basal joint are in balanced tonic contraction.

Several vertical sequences were timed in one animal; each required from 3 to 6,5 sec for completion.

Horizontal sequence. The horizontal sequence involves movement at all the antennular joints. Starting with basal and second segments pointing forward and third segment elevated, the following sequence is typical. A lateral movement at the first joint between the basal and second segments is closely followed by lateral movement at the basal joint. While the basal and second segments are progressing laterally, the third segment is depressed. These overlapping actions result in a smooth downward and lateral movement of the antennular flagella, carrying them beneath the antennae and pointing them out from the sides of the cephalothorax. At the end of the lateral excursion there may be a slight elevation of the third segment, but usually medially directed movements at the basal and then the first joint bring the antennule back forward under the antennae and finally, elevation at the second joint completes the sequence. The contraction order of the muscles of the basal and first joints may vary. Although it generally repeats in a given animal, the two joints at times begin movements almost simultaneously, and in some animals, the basal joint may clearly initiate both lateral and medial movements. In any case, the resultant movement of the antennular flagella appears essentially the same, a smooth lateral sweep of over $90^{\circ}$ associated with a vertical component at the forward position.

Antennular flicking during the sequence was variable, but usually occurred during or slightly before depression of the third segment. It also occurred occasionally at the end of the lateral excursion and during the return to the forward position. One got the impression that maintained depression of the outer flagellum often correlated with depression of the third segment.

Where measured, the time required for completion of one horizontal sequence was similar to that for the vertical sequence.

At this point it must be emphasized that antennular movements are not as rigidly defined as the above descriptions might suggest. The 
vertical and horizontal sequences are best considered basic patterns followed in the absence of specific stimulation, for although they are definite and can be observed repeatedly, all variations and intergrades may occur. A cycle may be interrupted or stopped at almost any point, and quite different arhythmic patterns of activity are often interposed. Most commonly, the relative extent of movement at any of the four joints may vary from one cycle to the next. In the extreme case, the horizontal sequence is essentially converted into the vertical sequence by immobilization of the basal and first joints. The movements of the two antennules appear independent of each other, offering little indication of close bilateral reflex integration or synchronization.

Reflex activity. The antennules, one of the major sensory appendages of the lobster, are involved in a number of reflexes and behavioral sequences. Those most relevant to the present discussion are briefly described below.

The stimuli used were of two general classes:

1. Mechanical stimulation in the form of taps or strokes of a clean glass rod, or of touch with a clean cloth swab.

2. Chemo-tactile stimulation in the form of touch with a cloth swab soaked in fish juice. Although the tactile component of the latter may introduce certain response patterns not present following chemical stimulation alone, these differences are not germane to the major argument and were not systematically explored.

Fast withdrawal reflex (antennule). This reflex is unilateral and consists of a rapid, twitch-like withdrawal of the stimulated antennule. It may be elicited by both chemo-tactile and mechanical stimuli applied to the antennular flagella. In the latter case, sudden taps seem most effective. With maintained contact the reflex usually occurs on first touch only.

The exact form of the reflex varies according to the flagellum stimulated. Outer flagellum: The most consistent component of the response is a brief inward and downward twitch of the basal antennular segment. Usually a lateral movement of the second segment, a downward movement of the third segment, and a brief depression of the outer flagellum are associated with this. Inner flagellum: The movement of the basal segment lacks the downward component and thus is an almost pure inward twitch. The second segment again flexes laterally, but the third segment is markedly elevated, not depressed. The inner flagellum generally seems less effective than the outer in initiating a fast withdrawal reflex.

Pointing movements. These and the following movements are less stereotyped and more complex than the fast withdrawal reflex. They 
occur less regularly and seem more dependent upon the "internal state" of the animal.

In these experiments antennular pointing movements were usually elicited by visual or chemical stimuli (see LINDBERg 1955). Normally they did not follow mechanical stimulation alone. In pointing, both antennules were extended toward the source of the stimulus, often with partial depression and/or flicking of the outer flagellum. With chemical stimuli it was usual for one antennular flagellum to be stimulated first or to be nearer the origin of the stimulus. Under such conditions, the more distant antennule moved over so that flagella of both antennules came into the region of the stimulating agent. Antennular pointing was often a component of the more complex exploring-feeding sequences described below.

Cleaning movements. The cleaning sequence begins with depression of the antennule, particularly the third segment and outer flagellum. The flagella are then grasped, brought down, and eventually drawn up between hairy pads on the inner surface of the carpus of each third maxilliped. This action may be repeated two or three times in succession, but in our experiments, one cleaning stroke was usual. In those cases where close observation was possible, one or the other of the two flagella usually passed directly through the cleaning pads, but not both.

Cleaning occasionally occurred in the absence of apparent stimuli or following mechanical stimulation. It was most commonly elicited, however, by chemical or chemo-tactile stimuli. Often cleaning followed the presumed stimulus with a latency of tens of seconds.

The cleaning response differs from the two preceding in that it requires integrated movement of appendages other than the antennules alone. Not only are the third maxillipeds, and occasionally the first pereiopods, brought into active antennular manipulation, but other appendages are involved in maintenance of the appropriate bodily posture during cleaning.

Bodily withdrawal. The movement sequences grouped under this class are heterogeneous, but all have the general effect of withdrawing the total organism from the region of the stimulus. Under appropriate conditions they may be elicited by both mechanical and chemo-tactile stimuli, as well as almost any other kind of stimulus applied to any part of the body.

The startle reaction is characterized by a single, synchronized twitchlike contraction of most of the appendages. It is often associated with the antennular fast withdrawal reflex, and involves both antennae and walking legs. The net effect is a sudden, limited withdrawal of the animal from the stimulus situation. 
The tonic withdrawal is characterized by maintained slow flexions or extensions of the appropriate appendages. Those on the stimulated side usually extend, those on the unstimulated side flex so the animal is drawn down and away from the stimulus.

Stepping withdrawal reactions include all active locomotory retreat from the stimulus area. Often this involves a few backward steps followed by turning and forward movement away from the stimulus.

Although each of the above reactions may occur alone, they often follow in sequence. Initial contact with an antennule may elicit the startle reaction. With maintained or repeated contact, tonic withdrawal becomes apparent, and with more prolonged or stronger stimuli, active stepping withdrawal movements begin. In most animals bodily withdrawal often involves various ill-defined combinations of these movements, so distinction of the component reactions is generally omitted in the following analyses.

Feeding sequence. The complete feeding sequence, as initiated by antennular stimulation, might be described as follows. Upon contact of either antennular flagellum with the appropriate chemical or chemotactile stimulus, antennular pointing movements and elevation of the fore part of the body occur. Walking legs, usually of the homolateral side, are extended and moved forward into the stimulus area in exploratory movements. These may be accompanied by active forward stepping. As the pereiopod dactyls come into contact with the chemical stimulus, searching movements, i.e. extension and waving of the leg, increase in intensity and extent. Upon contact with an object, searching movements terminate and grasping movements begin in which the dactyl flexes over the object and carries it toward the mouthparts. If the grasped object is the source of the chemical stimulus, other limbs, usually the first two or three pairs of walking legs, are brought over to help direct the object toward the mouthparts where it is eventually accepted or rejected (see BETHE 1897). If rejected, searching and grasping begin again and continue until an acceptable object is retained or until the stimulus dissipates or the animal accomodates. Fig. 3 summarizes the presumed sequence outlined above. There are at least three critical points where the movements alter in quality: 1 . at the initiation of searching movements, 2. at the shift from searching to grasping activity, and 3. at the shift from grasping to feeding.

The extent to which the above sequence of activity is realized in detail depends upon a number of factors; among others, the strength of the stimulus, the duration of pretest fasting, and the physiological state of the animal (see below). Very commonly, when vigorous responses occur the initial antennular movements are omitted, and the animal immediately springs forward with extended pereiopods. Incomplete 
grasping is interspersed with the searching movements. At the other extreme, when responsiveness is low, the sequence can stop after weak pointing reactions and slight bodily elevation, or it may continue briefly with incipient searching or pereiopod extension that fails to reach the stimulus area. The feeding sequence also habituates with repetition. In one animal, for example, six stimuli were presented to the same

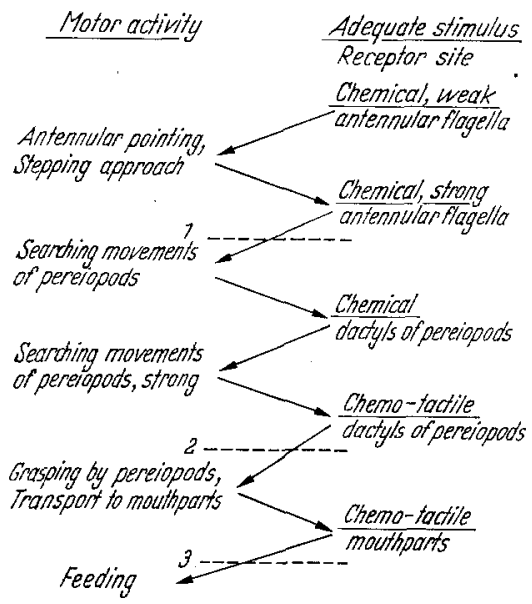

Fig. 3. Propesed chain of sensory and motor activity involved in initiation of feeding activity via antennular stimulation. Each stimulus leads to motor activity which in turn facilitates the subsequent stimulus of the chain. Levels 1,2 , and 3 indicate the points in the chain where activity alters in quality, involving either new structures or totally new patterns of movement antennular flagellum at spaced intervals within three and onehalf minutes total time. The first three stimuli elicited full feeding responses, the first being the strongest. Cleaning movements followed the feeding activity of the third stimulus, and the responses to the fourth and fifth did not continue beyond incipient searching activity. The sixth stimulus was completely ineffective.

Even without obvious habituation, the feeding response did not always follow every presentation of a presumably adequate stimulus. To control for failures because of generalized disinterest in food and/or inability to perform the motor movements necessary for feeding, the responsiveness of a later, apparently more stable component of the feeding sequence was examined. This is the dactyl grasp reflex. As described below it was used as an empirical estimate of food interest.

Pereiopod reflexes. With a few exceptions, mechanical stimulation of a dactyl resulted either in no response or withdrawal of the stimulated leg. When combined with chemical stimulation, however, as with a swab soaked in fish juice, touch of the dactyl ordinarily caused grasping movements and attempts to carry the swab to the mouthparts. This is the dactyl grasp reflex. As mentioned above, the two or three pairs of appendages bordering the one originally stimulated were often brought into activity with strong stimuli or in animals with low threshold. The grasping reflex could be elicited from all five pairs of pereiopods, but the more anterior seemed most effective, the fifth pair the least. Fish juice alone elicited searching activity when pipetted over the dactyls. 
Physiological state. There are two physiological periods when the lobster shows no interest in feeding; immediately before molting and immediately after molting.

Postmolt period. For the first two or three days following molt the exoskeleton remains quite soft and the lobster tends to remain motionless. During this time it responds to tactile and chemo-tactile stimulation of either antennules or dactyls with withdrawal reflexes. No indication of grasping or feeding is evident, and food placed in the vicinity is not eaten (see Travis 1954). The exact duration of this fasting period is not certain and probably varies among lobsters. One animal showed grasping reflexes approximately 44 hours after molt and fed within 60 hours while another specimen still had no interest in food after 77 hours. Many gave grasping reflexes within five days.

Premolt period. Softening of the lower edges of the carapace and resorption along the ecdysal line begin several days before molt (Travis 1954). The number of animals tested in this period is small, but results consistently show absence of feeding or grasping responses. Indeed the only response obtained from one animal was the antennular withdrawal reflex; chemotactile stimulation of the dactyls elicited no response whatso-ever. Such premolt animals are very alert, however, and some show evidence of unusual aggressiveness, moving forward and striking with the antennae upon visual or chemo-tactile stimulation (see ScHÄFER 1957; quoted in ScHöNE 1961). No animals were carried through molt, but several were followed for up to five days. The premolt fast must therefore last at least that long, and the state of the ecdysial line at the end of observation suggests that the duration may be even longer.

\section{Post-operative behavior}

Removal of one eyestalk caused an immediate and lasting change in resting and locomotory posture. The lobster tipped toward the operated side. Although circusing tendencies were not examined, general mobility seemed unaffected and major changes in other behavior were not obvious in casual observation.

Primary attention was directed to the effects of the ablation upon antennular function, particularly with respect to its effectiveness as a trigger for feeding responses. Several groups were examined at varying intervals following the operation. Deficiencies in certain evoked responses were more apparent than were disturbances in spontaneous activity. In fact, upon gross observation, spontaneous antennular movements seemed essentially unaffected. The results are summarized in Tables 1-4 and considered in more detail in the sections below. 


\section{Response to tactile or mechanical stimulation (Table 1)}

Five post-operative lobsters were tested with mechanical stimulation of the outer antennular flagellum. Two were examined 16 days after the operation and three, 145-161 days post-op. Animals 0-8 and 0-9 had regenerated a heteromorphic antennular outer flagellum in place of the amputated eye at the time of testing.

Table 1. Effectiveness of mechanical stimulation in eliciting antennular, dactyl, and feeding responses

\begin{tabular}{|c|c|c|c|c|c|c|c|c|c|c|}
\hline \multirow{2}{*}{$\begin{array}{l}\text { Spec-- } \\
\text { imen }\end{array}$} & \multirow{2}{*}{ Date } & \multirow{2}{*}{$\begin{array}{l}\text { Post- } \\
\text { op. } \\
\text { (days) }\end{array}$} & \multirow{2}{*}{$\begin{array}{l}\text { Post- } \\
\text { molt } \\
\text { (days) }\end{array}$} & \multicolumn{5}{|c|}{ Antennule } & \multicolumn{2}{|c|}{ Dactyl } \\
\hline & & & & reflex & point & clean & retreat & feed & grasp & retreat \\
\hline $0-6$ & $8-18$ & 16 & & A-I & & & A-I & 0 & 一 & \\
\hline $0-7$ & $8-18$ & 16 & & A-I & & & A-I & 0 & - & \\
\hline $0-8^{\prime}$ & $8-9$ & 145 & 2 & A-I & & (A) & A-I & 0 & & $\mathrm{~S}$ \\
\hline & $8-13$ & 149 & 6 & A-I & & & $(\mathrm{I} / \mathrm{A})$ & 0 & & 一 \\
\hline $0-9^{\prime}$ & $8-9$ & 145 & 5 & A-I & & & Á-I & 0 & & $\mathrm{~S}$ \\
\hline 0.10 & $8-25$ & 161 & 16 & A-I & & & A-I & 0 & $\mathrm{w}$ & \\
\hline
\end{tabular}

Legend. (Applies to all four tables.)

Specimen. N, normal lobster with intact antennules and eyestalks; NA, lobster with distal segment and flagella of one antennule removed, tested after partial regeneration; $O$, lobster with one eyestalk removed; $O A$, lobster with one eyestalk and one antennule removed, tested after partial regeneration of antennule; ', heteromorphic antennular flagellum growing in place of ablated eyestalk.

Postmolt. 2nd, when two molts occurred since ablation, the time since the second is indicated.

Antennule. A, stimulation of outer antennular flagellum on ablated side; I, stimulation of outer antennular flagellum on intact side; - n, normal, unregenerated antennule; $-r$, partially regenerated antennule.

The designations under each specified antennular response have the following meanings: no symbol or 0 , response not elicited by antennular stimulation; A-I, antennular stimulation on ablated and intact side equally effective; $\mathrm{A} / \mathrm{I}$ or $\mathrm{I} / \mathrm{A}$, stimulation of the first designated antennule more effective than the second; $A$ or I, only designated antennule effective; ? in place of A or I, response probably occurred but was not observed; ( ), weak or questionable response to the indicated stimulation.

Dactyl. 0, no response to dactyl stimulation; S, strong response; w, weak response or high threshold for designated motor activity; --, dactyl not tested.

Series of mechanical stimuli (touch or tap with glass rod or clean swab) were applied to right and left flagella alternately. Responsiveness varied among individuals, and at different times in the same individual so that the relative effectiveness of stimuli applied to opposite flagella within a brief period of time proved to be the only reliable estimate of operationally induced asymmetries in this and the following test sequences. Table $I$ shows that in all animals, stimulation of the flagellum on the amputated side was equivalent to stimulation of the flagellum on the intact side in evoking the fast antennular withdrawal reflex (ant. reflex). The two flagellae also seem about equivalent in their 
ability to initiate bodily withdrawal. Feeding responses were never initiated by mechanical stimulation of the flagella. In one animal, a cleaning reflex occurred after the termination of a prolonged series of mechanical stimuli applied to inner and outer flagella on the amputated side. This response was not repeated.

In two animals, mechanical stimulation of a dactyl with a glass rod caused withdrawal of the leg; in one animal, stimulation with a clean cloth swab caused a weak grasping reflex.

It seems evident that unilateral eyestalk ablation does not interfere with activity normally initiated by mechanical stimulation of either antennule. Nor is mechanical stimulation alone effective in triggering feeding activity.

\section{Responses to chemo-tactile stimulation (Table 2)}

Ten lobsters were tested for asymmetrical evocation of the feeding sequence after removal of one eyestalk. Swabs soaked in fish juice were applied to the outer flagella of the antennules. Five animals were tested 12-48 hours after the

Table 2. Effectiveness of chemo-tactile stimulation in eliciting antennular, dactyl, and feeding responses in normal and postoperative animals

\begin{tabular}{|c|c|c|c|c|c|c|c|c|c|c|}
\hline \multirow{2}{*}{$\begin{array}{l}\text { Spec- } \\
\text { imen }\end{array}$} & \multirow{2}{*}{ Date } & \multirow{2}{*}{$\begin{array}{l}\text { Post- } \\
\text { op. } \\
\text { (days) }\end{array}$} & \multirow{2}{*}{$\begin{array}{c}\text { Post- } \\
\text { molt } \\
\text { (days) }\end{array}$} & \multicolumn{5}{|c|}{ Antennule } & \multicolumn{2}{|c|}{ Dactyl } \\
\hline & & & & reflex & point & clean & retreat & feed & grasp & retreat \\
\hline N-1 & $8-14$ & - & & both & $?$ & both & & both & $\mathrm{S}$ & \\
\hline $\mathrm{N}-2$ & $8-14$ & - & & both & both & both & & both & $\mathrm{s}, 0$ & \\
\hline $\mathrm{N}-3$ & $8-14$ & - & & both & $?$ & both & left & both & $\mathrm{S}, 0$ & \\
\hline $\mathrm{N}-4$ & 8-14 & - & & both & & & both & 0 & $w$ & $\mathrm{~S}$ \\
\hline $0-1$ & $8-25$ & $<1$ & & A-? & $?$ & A & & $\mathrm{I} / \mathrm{A}^{*}$ & $\mathrm{~S}$ & \\
\hline & $8-26$ & 1 & & A-? & ? & A & & I/A* & - & \\
\hline $0-2$ & $8-26$ & 1 & & A-? & ? & A & & I & 一 & \\
\hline $0-3$ & $8-26$ & 1 & & $\bar{A}-\mathrm{I}$ & & & & $\overline{\mathbf{I}}$ & $\mathrm{S}$ & \\
\hline $0-4$ & $8-27$ & 2 & & A-? & $?$ & A & & $\mathrm{I} / \mathrm{A}^{*}$ & - & \\
\hline $0-5$ & $8-27$ & 2 & & A-? & $?$ & A & & $\mathrm{I} / \mathrm{A}^{*}$ & - & \\
\hline $0-6$ & $8-18$ & 16 & & A-I & & I & $(\mathrm{A}-\mathrm{I})$ & $\mathrm{I}-\mathrm{A}$ & $\mathbf{w}$ & $\mathrm{S}$ \\
\hline $0-7$ & 8-18 & 16 & & A-? & I-A & A & & $\mathrm{I}$, & $w$ & \\
\hline $0-8^{\prime}$ & 8.9 & 145 & 2 & A-I & I & $\mathrm{I}$ & $\mathrm{A} / \mathrm{I}$ & $\mathrm{I} / \mathrm{A}$ & $\mathbf{S}$ & \\
\hline & $8-13$ & 149 & 6 & A-I & I-A & & A-I & I & $\mathbf{S}$ & \\
\hline $0.9^{\prime}$ & $8-9$ & 145 & 5 & A-I & $\mathrm{A}$ & I & A & $\mathrm{I} / \mathrm{A}$ & $\mathrm{S}$ & \\
\hline & 8.14 & 150 & 10 & A-I & $\mathrm{A} / \mathrm{I}$ & I-A & I & 0 & $\mathrm{~S}$ & \\
\hline & $8-15$ & 151 & 11 & A-I & & & A-I & 0 & $\mathrm{~S}$ & \\
\hline 0.10 & 8.14 & 150 & 5 & A-I & I-A & I-A & $\bar{A} / \bar{I}$ & $\mathrm{I} / \mathrm{A}$ & $\mathrm{S}$ & \\
\hline & $8-25$ & 161 & $\begin{array}{c}(2 \mathrm{nd}) \\
16 \\
(2 \mathrm{nd})\end{array}$ & A-I & & & (A) & I & 一 & \\
\hline
\end{tabular}

See legend of Table 1.

* Incipient feeding response following stimulation of " $A$ " antennule was directed toward the intact side, i.e. away from the stimulus. 
operation, the remaining five were examined from $16-161$ days post-op. Four nonoperative controls included for comparison show the normal symmetry of response to antennular stimulation.

The observations summarized in Table 2 show that unilateral removal of an eyestalk greatly impairs, and in some cases, apparently abolishes, the ability of the antennule on the operated side to trigger the feeding sequence in response to normally adequate stimuli. This impairment appears shortly after the operation - the earliest tests were made after about 12 hours - and continues without obvious remission for up to 161 days and over two molts. The impairment seems limited to the triggering of the feeding sequence, for all responses associated with the mechanical aspect of the stimulus remain unaffected, and both pointing and cleaning activity also occur. Three typical excerpts (paraphrased) from the protocol illustrate the observations on which Table 2 is based. The notes and comments were added after completion of the observations.

Excerpt 1. Lobster O-2. Left eyestalk removed morning of August 25. Placed in test aquarium evening of August 25, unresponsive at that time.

Test. August 26, 1962. After 4:00 pm. Stimulus: small cotton swab dipped in fish juice.

I. Stimulate outer flagellum of left antennule ("A"), two touches. Each produced ant. reflex; clean left antennule after second touch. Grasping and feeding with dactyles of first two pairs of legs after cleaning.

(Added note: When dactyls were brought up in the cleaning activity, they apparently came into direct contact with fish juice diffusing from the swab.)

II. Stimulate outer flagellum of right antennule ("I"), one stroke. Immediate raise and advance, grasping. The legs on the right side are lifted first.

III. Stimulate " $A$ ", one stroke. Ant. reflex, first two pairs of legs lifted in beginning of cleaning activity. Left antennule brought down to clean, but before this could be completed, shifted stimulus to stroke " $T$ ". Immediate interruption of cleaning activity, feeding response with lifting of right appendages.

IV. Stimulate " $I$ ". Ant. reflex, lifting of cephalothorax, reaching and grasping activity.

Comment. In some instances grasping begins immediately after stimulation of "I" so that the ant. reflex, if present, cannot be observed.

Excerpt 2. Lobster O-6. Right eyestalk removed August 2. Test: August 18, 1962. Stimulus: small cotton swab dipped in fish juice.

10:40 am. Animal crouched in corner of test aquarium with the left or nonoperated side noticeably higher than the right.

11:06 am. Touched outer flagellum of left antennule ("I"). Almost immediate "leap" forward, reaching, grasping .with. all legs followed by active exploration of tank.

11:15 am. Touched outer flagellum of right antennule (" $A$ "). Almost immediate reaching and grasping. The animal was actively exploring when stimulated.

11:16 am. Touched "I" while animal was exploring, same effect as observed at $11: 15$ with "A".

$2: 33 \mathrm{pm}$. Animal alert, on toes in corner of test aquarium. Stimulate "A". Ant. reflex with one or two slight startle responses. 
2:35 pm. Stimulate "T". Ant. reflex. Cleaned antennule five times after third contact with swab. With continued touches, antennular reflexes and a slight startle reaction.

$2: 38 \mathrm{pm}$. Touch dactyl of left first pereiopod. Weak grasping and attempt to draw swab toward mouth. Touched dactyl of third left pereiopod. Withdraw leg and side-stepped from stimulus.

Comment. This animal was more inconsistent than usual, and ambiguous dactyl reflexes suggest that it was not in a stable physiological state. The positive response from " $A$ " stimulation at 11:15 is not completely reliable because it was not repeated and the slight delays in response may have been sufficient for diffusion of juice from the swab to non-antennular receptors. In general, the effective stimulus could be considered well localized only when the evoked responses had very short latencies.

Excerpt 3. Lobster 0-10. Left eyestalk removed March 17, 1962.

Test. August 14, 1962. Stimulus: Small cotton swab dipped in fish juice.

$5: 03 \mathrm{pm}$. Animal alert and on toes in test aquarium.

5:05 pm. Stimulate outer flagellum of left antennule ("A"). Ant. reflex, slight bodily withdrawal. Right antennule points, followed by lifting of cephalothorax and some exploratory movements.

(Added note: Lifting and exploring may have been mediated via right antennule as it passed into stimulus area when it pointed.)

5:08 pm. Stimulate outer flagellum of right antennule ("I"). Ant. reflex, left antennule points. Cephalic lifting, first and second right legs reach forward. Clean right antennule.

5:09 pr. Stimulate "A". Ant. reflex, stepping withdrawal. Clean left antennule. Move stimulus to " $I$ ". First and second legs on right side lift-and reach forward. Then stepping withdrawal continues.

$5: 10 \mathrm{pm}$. Stimulate "A". Ant. reflex, bodily withdrawal, clean left antennule, point with right antennule. Touch " $I$ " immediately afterward. Forward rush and reaching by all pereiopods. Strong feeding response.

5:13 pm. Repeat "A" twice, reflex only on each. Repeat "I" twice. Both times, slight cephalothorax lift, and on first stimulus, lift of pereiopods $1-3$ on right side.

$5: 14 \mathrm{pm}$. Touch dactyl of second right pereiopod, grasping by pereiopods.

Comment. Although there is some variability and stimulation of " $\mathrm{I}$ " does not always evoke the complete feeding response, " $\mathrm{A}$ " is essentially ineffective. This animal shows well defined asymmetry.

Since formal statistical comparisons between control and test groups were not practical with the data at hand, the reasons for assuming that asymmetry of feeding initiation results from impairment of the operated side rather than hyperexcitability of the intact side need to be indicated.

1. Complete feeding activity was almost never elicited from the antennule on the operated side, even when good dactyl grasp reflexes indicated that the animal was in a favorable state. Moreover, the form of the response in several of those cases in which " $A$ " appeared effective (see Table 2, 0-6 and 0-10) was such that diffusion may have invalidated the apparent localization of the stimulus. This behavior contrasts with the regularly elicited feeding activity in the control group. 
2. Both the intensity of the feeding response and the frequency of its initiation appeared alike in control group and intact side in post-op. animals. The possibility of minor fluctuations due to the operation cannot be excluded, but they could not be of sufficient magnitude to discount the conclusion that the major effect of eyestalk. removal is unilateral reduction, not augmentation, of feeding activity.

The frequencies of antennular pointing and cleaning in response to chemo-tactile stimuli are similar for normal animals and "intact" and "ablated" antennules in late post-op. animals. This indicates that loss of the ability to initiate complete feeding in the operated animals was not associated with a total loss of the "chemical" sense. Although intramodality discrimination tests were not used, the lobsters clearly distinguish in their behavior between the object presented with, and the object presented without concomitant chemical stimuli.

When tested one or two days after the operation, four of the five experimental lobsters showed marked asymmetry in initiation of antennular cleaning activity. Not only was cleaning initiated exclusively by the antennule on the operated side, but it occurred much more frequently and with less intense stimulation than found in the control group (Table 2). Apparently unilateral eyestalk ablation causes a temporary increase in homolateral antennule cleaning tendencies as well as a more permanent interruption of the feeding response. Other than the feeding sequence, however, asymmetrical responsiveness was not prominent in animals examined several days after the operation, at least with respect to the reflexes under consideration in this paper.

\section{Effects of unilateral antennular ablation}

Removal of an eyestalk is followed by extensive degeneration and reorganization in the remaining central regions of the brain (HERBST 1916). There is the possibility, therefore, that the phenomena reported above do not result from interruption or removal of a specific neural area or pathway in the eyestalk, but from a more generalized disturbance of the central olfactory regions. This is perhaps unlikely in view of the rapid appearance of the defect, but it is pertinent to ask whether central reorganization produced by ablation of other cephalic sensory structures causes the same responses.

One of the most direct, natural ways to disturb the organization of an olfactory center is to remove the antennule, or portions thereof, and to allow it to regenerate. Such an operation should require complete reestablishment of primary afferent connections from the flagella, and since the number of sensory endings on the first regenerate antennule is less than in the normal, considerable interneuron reorganization might be expected. The antennules normally do not autotomize. 
Accordingly, the flagella and distal half of the third segment of one antennule were successfully removed from 12 lobsters (Fig. 4). In four controls, the eyestalk was left intact; in three, antennule and eyestalk of the same side were removed; and in five, antennule and eyestalk of opposite sides were amputated. Lobsters were tested in the usual manner after one or two post-operative molts. Flagella regenerated in all cases, and in four instances, heteromorphic flagella were also present growing from the stump of the am. putated eyestalk.

\section{Response to tactile or mechanical stimulation} (Table 3)

Six lobsters were tested with pure mechanical stimuli. The observations are sum. marized in Table 3 . On the whole, the results appear similar to those of Table 1. Certainly the responses of $\mathrm{OA}-5$, OA-6, OA-8, and OA-3 seem normal. There are, however, two significant exceptions. The form of the fast antennular withdrawal reflex of the

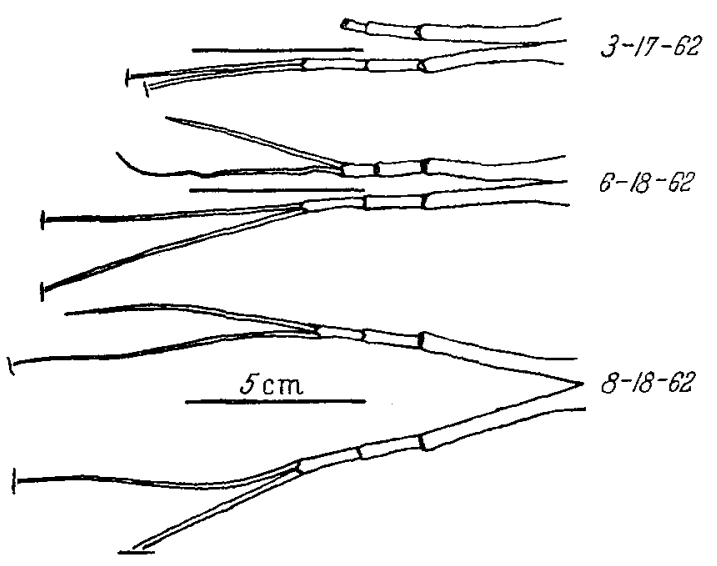

Fig. 4, Ablation and regeneration of flagella and distal half of third segment of right antennule. Dorsal view, normal antennule included as control at each stage. $3-17-62$, date of ablation; $6-18-62,93$ days postop., date of first molt. Flagella and third segment regenerated but they and the second segment are reduced in length. 8-18-62, 154 days post-op., 61 days postmolt, date of second molt. Regenerated segments show disproportional growth, but are still sub-normal. Length calibration is $5 \mathrm{~cm}$ in each instance. Outlines traced from photos

regenerate antennules is abnormal in both OA-2 and OA-7. Relative sensitivity in OA-2 appears unaltered, but reflex movement generally occurs only at the basal joint of the regenerate antennule; both second and third joints remain stiff (see above for normal reflex). In OA-7, on the other hand, the reflex movements at all joints of the regenerated antennule were much stronger than normal, and were more frequently followed by general bodily withdrawal. The normal habituation of the antennular reflex to repeated stimulation was absent or much reduced in the regenerate, and more time was required for recovery from a single reflex twitch, i.e. the second and third joints often remained in spastic contraction for two to three seconds. Thus it seems that perfect reestablishment of centers governing antennular integration may not always occur after ablation and regeneration of portions of one antennule (at least within a five month period). The normal antennule gave normal responses in all cases. 
Table 3. Mechanical stimulation of antennules in lobsters with one regenerate antennule

\begin{tabular}{c|c|c|c|c|c|c|c|c|}
\hline $\begin{array}{c}\text { Spec- } \\
\text { imen }\end{array}$ & Date & $\begin{array}{c}\text { Post- } \\
\text { op. } \\
\text { (days) }\end{array}$ & $\begin{array}{c}\text { Post- } \\
\text { molt } \\
\text { (days) }\end{array}$ & \multicolumn{4}{|c|}{ Antennule } & \multicolumn{2}{|c|}{ Dactyl } \\
\cline { 4 - 7 } & &
\end{tabular}

Eyestalk and antennule on opposite sides :

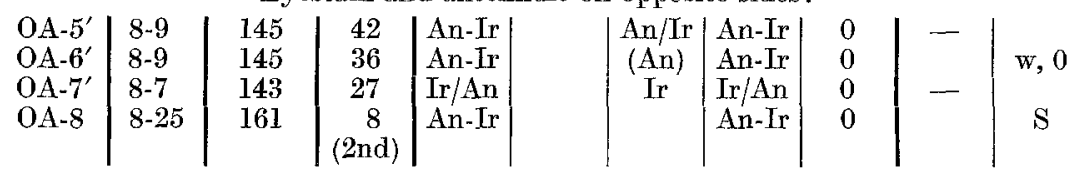

Eyestalk and antennule on same side:

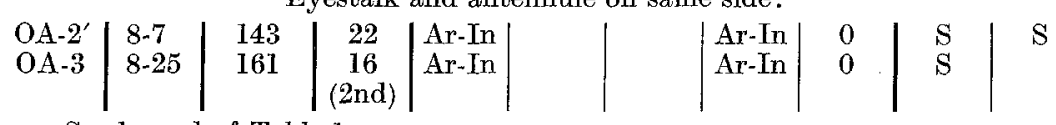

See legend of Table 1.

\section{Response to chemo-tactile stimulation (Table 4)}

When Table 4 is compared with Table 2 , it is evident that antennular regeneration usually causes no major alterations in the effects of eyestalk removal on initiation of the feeding sequence. On the basis of a single successful control animal, antennule ablation alone also has no major effect on relative effectiveness of antennules in initiation of feeding. Some details, however, must be discussed at greater length.

The number of animals which show weak or no dactyl responses and no feeding activity is larger than expected when compared with Table 2. This lack of responsiveness seems correlated with a stage in the molt cycle rather than antennular ablation. Upon dissection of NA-2 on August 29, a well-developed new cuticle and extensive resorption from the outer carapace were found. OA-l showed resorption from the ecdysal line by August 30 and molted sometime during the first few days of September. Both of these animals were therefore in the premolt fast when tested. It is reasonable to assume that lobsters NA-1, NA-3, and OA-4 were also approaching molt, for their postmolt period of 67 days or more was similar to that of NA-2 and OA-1 and is longer than reported average summer intermolt periods (TRavis 1954). In NA-4 and OA-3, on the other hand, the absence of feeding five days after molt suggests a prolonged postmolt fast.

It should be noted that normal and regenerate antennules of OA-1 were equally effective in eliciting aggressive advance and antenna strikes. Since one eyestalk was also removed, this animal serves as control for the remote possibility that the interruption of feeding initiation by eyestalk removal is due to interference in motor integration controlling approach or advance per se.

Two animals showed atypical feeding initiation which could not be explained by molt cycle alone. In both, the ablated eyestalk and 
Table 4. Chemo-tactile stimulation of antennules in lobsters with one regenerate antennule and one missing eyestalk

\begin{tabular}{c|c|c|c|c|c|c|c|c|}
\hline \multirow{2}{*}{$\begin{array}{c}\text { Spec- } \\
\text { imen }\end{array}$} & Date & $\begin{array}{c}\text { Post- } \\
\text { op. } \\
\text { (days) }\end{array}$ & $\begin{array}{c}\text { Post- } \\
\text { molt } \\
\text { (days) }\end{array}$ & \multicolumn{4}{|c|}{ Antennule } & \multicolumn{2}{|c|}{ Dactyl } \\
\cline { 5 - 7 } & & reflex & point & clean & retreat & feed & grasp & retreat \\
\hline
\end{tabular}

Amputated antennule only:

\begin{tabular}{|c|c|c|c|c|c|c|c|}
\hline NA-1 & $8-27$ & 163 & $71^{+}$ & $\mathrm{r} / \mathrm{n}$ & & 0 & $w$ \\
\hline $\mathrm{NA}-2$ & $8-27$ & 163 & $71^{+}$ & $\mathrm{r}-\mathrm{n}$ & & 0 & 0 \\
\hline $\mathrm{NA}-3$ & $8-28$ & 164 & 67 & $r-n$ & & $(r-n)$ & 0 \\
\hline NA-4 & $8-14$ & 150 & 5 & $\mathrm{r}-\mathrm{n}$ & $(\mathrm{n} / \mathrm{r})$ & 0 & 0 \\
\hline & $8-27$ & 163 & 18 & $\mathrm{r}-\mathrm{n}$ & $\mathrm{r}-\mathrm{n}$ & $\mathbf{r}-\mathrm{n}$ & - \\
\hline
\end{tabular}

Eyestalk and antennule on same side:

\begin{tabular}{|c|c|c|c|c|c|c|c|c|c|}
\hline OA-I & $8-26$ & 162 & $70^{+}$ & $\mathrm{In} / \mathrm{Ar}$ & & & * & 0 & $w, 0$ \\
\hline $\mathrm{OA}-2^{\prime}$ & $8-7$ & 143 & 22 & Ar-? & Ar & & & $\mathrm{In} / \mathrm{Ar}$ & $\mathrm{S}$ \\
\hline & 8-14 & 150 & 29 & $A r-I n$ & & & & 0 & $\mathrm{~S}$ \\
\hline & $8-15$ & 151 & 30 & $\mathrm{Ar}-\mathrm{In}$ & In-Ar & & Ar-In & 0 & $\mathrm{w}$ \\
\hline & $8-19$ & 155 & 34 & Ar-In & (Ar) & & & $\mathrm{In} / \mathrm{Ar}$ & w \\
\hline $\mathrm{OA}-3$ & $8-14$ & 150 & 5 & $\operatorname{Ar}-\operatorname{In}^{1}$ & & & $\operatorname{Ar} / \operatorname{In}$ & $(\operatorname{Ar}-\mathrm{In})$ & $\mathrm{S}$ \\
\hline & $8-25$ & 161 & $\begin{array}{c}16 \\
\text { (2nd) }\end{array}$ & Ar-? & & Ar & & $\mathrm{In} / \mathrm{Ar}$ & S \\
\hline
\end{tabular}

Eyestalk and antennule on opposite sides:

\begin{tabular}{|c|c|c|c|c|c|c|c|c|c|}
\hline $\mathrm{OA}-4$ & $8-26$ & 162 & $70^{+}$ & An-Ir & & $A n-\operatorname{Ir}$ & & $\mathrm{Ir}$ & 0 \\
\hline & $8-27$ & 163 & $71^{+}$ & An-Ir & & An-Ir & & Ir & $\mathrm{S}$ \\
\hline OA-5' & $8-9$ & 145 & 42 & $?$ & & An & & $\operatorname{Ir} / \mathrm{An}$ & $\mathrm{s}$ \\
\hline$O A-6^{\prime}$ & 8-9 & 145 & 36 & An-Ir & $\mathrm{Ir}-\mathrm{An}$ & An-Ir & An-Ir & $\mathrm{Ir} / \mathrm{An}$ & S \\
\hline OA. $7^{\prime}$ & $\begin{array}{l}8-15 \\
8-7\end{array}$ & $\begin{array}{l}151 \\
143\end{array}$ & $\begin{array}{l}42 \\
27\end{array}$ & $\begin{array}{l}\text { An-Ir } \\
\text { An-Ir }\end{array}$ & Ir-An & $A n-I r$ & An-Ir & $\begin{array}{l}0 \\
0\end{array}$ & $\begin{array}{l}S \\
S\end{array}$ \\
\hline & $8-19$ & 155 & 39 & $\mathrm{An}-\mathrm{Ir}$ & & $\mathrm{An}-\mathrm{Ir}$ & An-Ir & (Ir) & $w, 0$ \\
\hline $\mathrm{OA}-8$ & $8-25$ & 161 & $\begin{array}{c}8 \\
(2 n d)\end{array}$ & An-Ir & An & An-Ir & $\Delta \mathrm{n}$ & $\operatorname{Ir} / A^{n}$ & \\
\hline
\end{tabular}

See legend of Table 1.

* This animal advanced and attacked swab and image of investigator. With repeated stimulation, withdrawal movements were interposed with the attacks.

1 Lateral movements at first joint of Ar are less prominent than those of In.

antennule were on opposite sides. The regenerated antennule of the first, OA-5, initiated normal feeding at reasonable levels of stimulation, but the opposite normal antennule on the eyestalkless side was also unusually affective (this is not indicated in Table 4). In the second, OA-7, normal feeding was not elicited by either antennule even though the regenerated antennule was abnormally responsive to mechanical stimulation. These two cases suggest that antennular removal may not always be without effect on the initiation of feeding responses, but the sample is too small and individual variability is too great (see OA-2) for such observations to be more than suggestive.

When all 12 animals are considered for all stimuli, only five showed clear evidence of semi-permanent central integrative disturbances

Z. vergl. Physiol. Bd. 46 
following unilateral antennular regeneration. In some, NA-1, OA-1, and $\mathrm{OA}-7$, this consisted of bilateral differences in responsiveness to mechanical (or chemo-tactile?) stimuli. In others, OA-2, OA-3, and $O A-7$, the movements of the regenerated antennule were abnormal either because of too little (OA-2, OA-3) or too much (OA-7) movement at the various antennular joints during the antennular withdrawal reflex.

To summarize this section, therefore, these observations offer little support for the hypothesis that the specific disturbances in initiation of feeding resulting from eyestalk ablation are caused by a general disturbance of the brain associated with regeneration or degenerative phenomena. They do indicate, however, that regeneration may sometimes lead to other abnormalities in central neural organization. These seem to involve either abnormal coordination of antennular motor movements or general alteration of many antennular functions, possibly including but not limited to the specific feeding sequence.

\section{Diseussion}

The changes in behavior which can be causally related to eyestalk removal are limited to relatively gross disruptions of normal behavioral symmetries. Thus, shifts in general responsiveness or loss of discrimination within a given sensory modality either went undetected, or if observed, could not be reliably ascribed to the operation. Several factors contributed to this limited behavioral resolution; the small sample sizes, the great individual variability, the lack of continuous observation for each lobster, and the uncertainty of the exact locus of the adequate stimulus or the effective receptor are among the most important. Where individual lobsters could be used as their own controls, however, certain behavioral changes were essentially universal for the populations examined (see Fig. 5), and these provide a relatively sound experimental basis for the following major conclusions:

I. Unilateral eyestalk removal "permanently" reduces the ability of the antennule on the operated side to initiate the normal feeding sequence in response to chemo-tactile stimuli.

II. Unilateral eyestalk removal does not abolish all effective chemical sensation in the antennule on the operated side, for after the operation chemo-tactile stimuli continue to be more effective in initiating specific responses than tactile stimuli alone.

III. Unilateral eyestalk removal does not appreciably alter the effectiveness of the antennule on the operated side in eliciting the normal responses which follow mechanical or tactile stimulation.

The term "permanent" as used in the above paragraph needs some qualification. The maximum operation-observation interval was 
166 days. Although this is long enough for two molts in some animals, it still is not long enough for an amputated antennule to recover full size, and central neural reorganization initiated by the eyestalk operation could conceivably still be in progress. It is premature to conclude that the antennular deficit imposed by eyestalk ablation will never be compensated, and indeed, partial compensation could have escaped detection in the present study. It is clear, however, that a deficit basic enough to

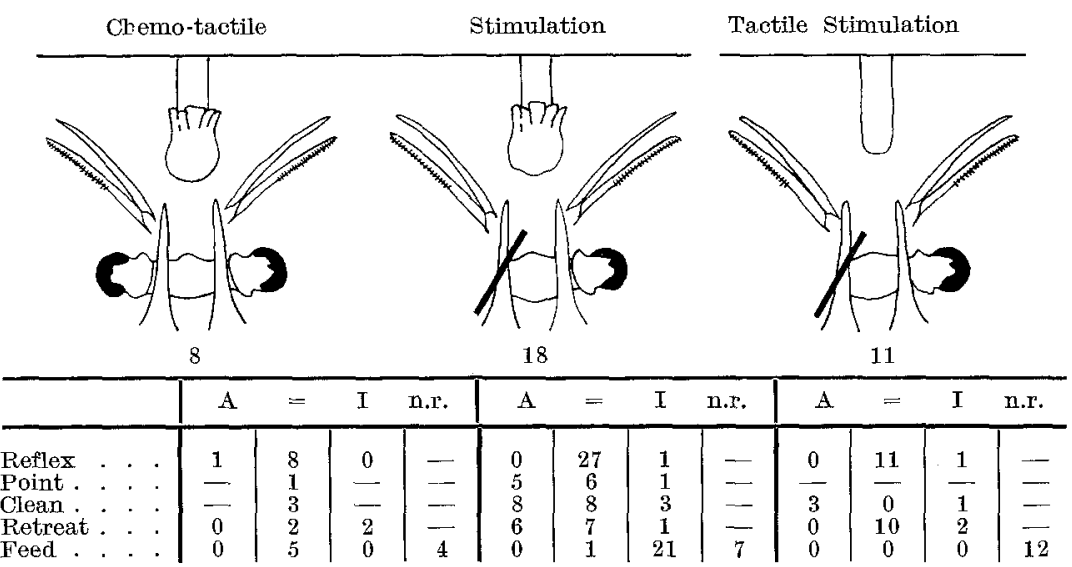

Fig. 5. Summary, effects of eyestalk ablation on antennular function. Three conditions are considered: I. control animals with intact eyestalks, chemo-tactile stimulation (8 individuals); II. experimental animals lacking one eyestalk, chemo-tactile stimulation (18 individuals); III. experimental animaIs lacking one eyestalk, tactile stimulation only (11 individuals taken from the preceding group of 18). Other variables, antennular ablation, post-operation time, etc. were ignored. For each condition the number of test series was determined in which each of five designated responses were elicited: 1 , most easily by stimulation of the antennule on the side lacking the eyestalk (column " $A$ "); 2 , with equal ease by stimulation of either antennule (column " =" ;) 3, most easily by stimulation if the antennule on the side with the intact eyestalk (column "I"); or 4, the response was not elicited by antennular stimulation (column "n.r."). Each animal was subjected to at least one test series, some to as many as four (Tables 1-4). A dash, "_,", indicates inadequate observation or absence of the appropriate test for a given response. Columns "A" and " $I$ " are interchangeable for the control condition, I. The asymmetry of pointing and retreat response initiation in Condition II is suggestive, but does not warrent further consideration at this time. See text and Table 4 for discussion of cleaning response asymmetry. The primary effect of eyestalk ablation on feeding initiation is clearly demonstrated

last several months should be distinguished from more transient effects and may involve a critical structural loss. The term "permanent" is used here for this purpose.

The only other antennular behavioral change presumed elicited by eyestalk ablation was transient rather than "permanent". It consisted of augmentation in frequency and vigor of cleaning the antennule on the operated side. This asymmetry was consistent enough in different individuals and definite enough in single animals to be accepted as a valid effect, but was present only for a few days following the operation (see Table 2). It is not clear whether the eventual compensation which 
was observed involved general recovery from a presumably altered central perception of the normal antennular input, or whether it involved specific habituation or accommodation of the mechanism initiating the cleaning response only.

Although this paper appears to offer the first clear evidence for an explicit, causal relation between eyestalk ablation and antennular dysfunction, occasional observations in the older literature were suggestive. In a paper describing the function of a heteromorphic antennule growing in place of one eye in a single crayfish, for example, Lissmann and WoLsKy (1933) observed that the normal antennule on the eyestalkless side, i.e. that of the heteromorph, was functionless and atrophic several months after the animal was brought to the laboratory. No specific reason for this effect was given. The observation that eyestalkless crayfish alter their feeding behavior (Scudamore 1947) may also be relevant to the present discussion.

Feeding activity in the spiny lobster involves a sequential interplay of adequate stimuli, simple stereotyped reflexes, and more labile integrative responses. In many ways it fulfills the ethological definition of an instinctive activity. Both our observations and a number of earlier studies on feeding behavior in other decapod Crustacea (BETHE 1897; Holmes and Homuth 1910) suggest that olfactory stimulation via the antennules normally initiates the sequence in the hungry animal. Appropriate chemical stimulation can be considered the releasing stimulus for the full sequence. Such antennular stimulation is also important in directing the animal toward the source of the stimulus. The effects of eyestalk ablation achieve particular significance, therefore, for on the basis of the above observations, the operation appears to produce a specific deficit in a higher order innate releasing mechanism. This central coordinating link rather than either the afferent or efferent patterning seems disrupted.

A second line of reasoning also suggests that the disruptive effect on antennular function of eyestalk ablation is largely confined to higher coordinating, command functions. The responses initiated by chemotactile stimulation of the antennular flagella may be arranged in a hierarchical order from simple to complex on the basis of the number of muscles and movements involved, the extent of spread to other segments, the duration of the response, and the lability of the activity. The fast antennular withdrawal reflex and antennular flicking would thus be at the bottom of the list; startle, pointing, cleaning, and complex withdrawal movements would be progressively higher; and searchingfeeding activity would be at or near the top. Searching activity is placed 
higher among the multisegmental responses because it is less stereotyped than cleaning activity and is initiated by more specific stimuli than the various withdrawal responses. It appears that neither the simpler reflexes from which the complex responses are composed, nor other similarly complex but different responses, i.e. cleaning or attack activity, are destroyed by the operation. Nor is feeding activity disturbed when elicited by the other antennule. The deficit again seems to occur in the higher integrative mechanism that coordinates a specific sensory input with the appropriate constellation of reflexes.

Eyestalk ablation not only removes an important portion of the central nervous system, the medulla terminalis and the three optic ganglia, but also halts visual input. In interpreting the mechanisms of the deficit, therefore, it is necessary to consider the possibility that ablation disrupts antennular function, not by removal of an anatomical portion of the integrative machinery, but by removal of a background barrage of impulses in afferent visual fibers that maintains the postulated higher olfactory center in the proper functional state. Such background activity could be considered analogous to the grid bias voltage of an electron tube. There is no direct evidence to discredit this possibility, but some restrictions are indicated. For example, in a few instances feeding activity in normal lobsters was initiated via antennular olfactory stimulation in the absence of a visual component. Similar experiments on Carcinus by BETHE (1897) also showed that specific visual cues need not be associated with chemo-stimulation for the antennules to elicit feeding, and furthermore, that blackening of the eyes did not disturb normal feeding. The postulated biasing input would therefore have to be insensitive to normal visual stimuli, i.e. pattern, light, and dark. Averaged resting discharge of visual fibers could conceivably serve this function, but the crucial experiments, progressive removal of the optic ganglia and medulla terminalis, remain to be done.

A more conventional and possibly more attractive explanation of the deficit is that eyestalk ablation does remove a critical portion of the higher olfactory "center" itself. In the absence of selective ablation experiments, the problem is to identify the most probable candidate for such a structure.

Published information on the detailed anatomy of the central nervous system of palinurans and most other decapod Crustacea is scanty and rather old. Fig. 6 is combined from the descriptions of BETHE (1895, 1897), Hanström (1928), Herbst (1916), and HeLm (1928) and is supplemented by our own observations on sectioned, Masson-stained material. It diagrams relevant neuropil regions and major connecting fiber tracts. It is not complete and is intended only to show the intimate, though 
indirect, connection between portions of the medulla terminalis and chemosensory fibers from the antennular flagella.

The sensory component of the antennular nerve contains both large and small diameter fibers. Many of the larger fibers originate in sensory hairs in the statocyst or in other antennular mechano-receptors. They terminate centrally in the antennular neuropil lying beneath the accessory lobe $\left(b_{1}\right.$ and $b_{2}$ of HELM 1928). Most of the smaller fibers probably arise in chemo-receptors situated on the antennular flagella and terminate in the olfactory lobe. The accessory lobe lacks primary sensory input (Helm 1928), but receives important fibers tracts, presumably first order internuncials, from the neighboring olfactory lobe. It also receives a compact fiber bundle from the longest, most obvious fiber tract in the brain, the olfacto-globular tract connecting the medial glomerular mass of the medulla terminalis with the olfactory-accessory neuropils. Many of the fibers of this tract that do not terminate in the accessory lobe continue past to originate in globular cell bodies at the ventro-lateral border of the olfactory lobe. These latter fibers presumably send collaterals into the two lobes, but their exact connections are uncertain. The direction of impulse flow in the tracts mentioned is also uncertain; in some it is probably bidirectional (see Fig. 6). It is important to note, however, that the bomolateral accessory lobe is the only one to undergo substantial reduction in size following unilateral eyestalk removal (HERBst 1916). Additional fiber tracts connect the olfactory and accessory lobes with other regions of the brain, but these can be omitted from discussion here. Neither lobe is known to have direct connections with the optic ganglia. The medulla terminalis is a heterogeneous neuropil having connections with the optic ganglia and midline brain structures such as the central body in addition to those with the accessory lobe via the olfacto-globular tract. It is, however, clearly the eyestalk structure having the most direct communication with olfactory imput from the antennules, and therefore represents the most likely candidate for the critical portion of the olfactory integrating system that is removed by eyestalk ablation.

Olfactory input to the accessory lobe and medulla terminalis is indirect, via first or second order internuncials. This and the fact that the neuropils are of the structured, glomerular type (see MaYNaRD 1962) largely formed from processes of globular internuncials led HANsTRöm (1928) and HExM (1928) to suggest that the medulla terminalis accessory lobe axis represents a higher order association system in the Crustacea. This is consistent with the nature of the defect reported in the present study. The medulla terminalis, however, is in close proximity to and receives extensive input from the optic ganglia, suggesting that 
its participation in higher order visual activity is also likely (see HANSTRöм 1925). One might expect to find the medulla terminalis particularly important in aspects of intermodality, olfactovisual integration.

Viallanes (1893), Hanström (1928), and others have indicated a number of anatomical similarities between the corpora pedunculata of

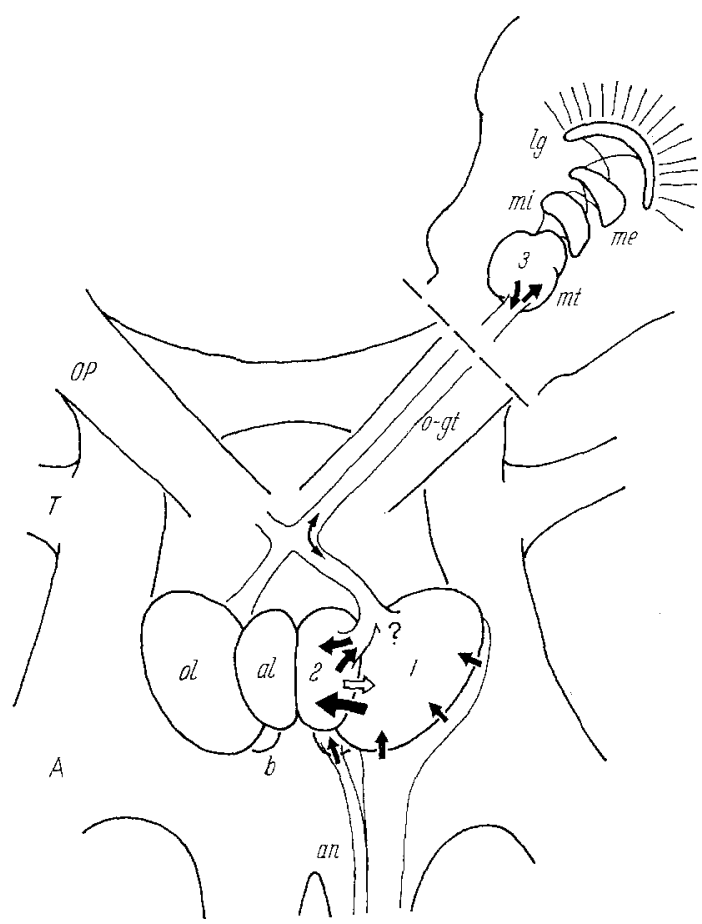

Fig. 6. Diagram of major neuropil areas and fiber tracts possibly involved in integration of olfactory information. Filled arrows indicate suggested direction of impulse flow from primary afferent fibere of the antennular nerve to and within higher olfactory centers. Open arrows indicate less certain directional paths, and the question mark (?) indicates still greater uncertainty. 1,2, and 3 possible relay stations or synaptic regions for impulses passing to and beyond the medulla terminalis. Feedback between 2 and 3,1 and 2 , or 1 and 3 may be possible. A antennal nerve; $a l$ accessory lobe; $a^{n}$ antennular nerve; $b$ deep-Iying antennular neuropil; lg lamina ganglionaris; me medulla externa; mi medulla interna; $m t$ medulla terminalis; $o l$ olfactory lobe; $o$ - $g t$ olfacto-globular tract; $O P$ optic peduncle; $T$ tegumentary nerve

the insects and the terminalis-olfactory lobe system in the Crustacea. This similarity apparently also extends to the function of the two systems, for in both the bee (VowLes 1954) and the cockroach (MAYNARD, unpublished observations) destruction of the calyces of the corpora pedunculata, i.e. those portions analogous to the medulla terminalis of the Crustacea, leads to disruption of the normal sensory or olfactory function of the antennae. 


\section{Summary}

1. Unilateral removal of the eyestalk (optic ganglia and medulla terminalis) in the Bermuda spiny lobster, Panulirus argus, disrupts normal initiation of feeding activity via chemo-tactile stimulation of the antennule on the side of the ablation. This deficit may be permanent for it has lasted without apparent remission for over five months and two molts.

2. Unilateral eyestalk ablation also produces a temporary increase in antennular cleaning activity directed toward the antennule on the side of the ablation. This effect seems to last for less than 16 days.

3. Unilateral eyestalk ablation does not appreciably disturb spontaneous antennular movements or responses to mechanical stimulation of the antennule on either side. Nor does it destroy the ability of the lobster to give differential responses to mechanical and chemo-tactile stimuli.

4. Most lobsters recover normal sensory and motor functions in antennules that regenerate after amputation of the distal segment and sensory flagellae. In about $1 / 3$ of the animals, however, some form of sensory or motor abnormality is evident in the regenerated antennule. These deficits are ascribed to occasional failure of regenerating neurons to reform appropriate central connections. They do not resemble the deficits following eyestalk ablation.

5. The medulla terminalis is tentatively proposed as the portion of the nervous system critical for normal antennular function that is removed by eyestalk ablation. There seem to be similarities between the effects of eyestalk ablation in the Crustacea as described here and the effects following destruction of portions of the corpora pedunculata in insects.

\section{Zusammenfassung}

1. Einseitige Entfernung des Augenstieles (optische Ganglien und Medulla terminalis) bei der Bermuda-Stachellanguste, Panulirus argus, unterbricht auf der operierten Seite den Beginn der normalen Freßtätigkeit, die durch chemische und taktile Reizung der Antennula eingeleitet wird. Diese Störung kann irreversibel sein, denn sie überdauerte in über 5 Monaten zwei Häutungen.

2. Einseitige Entfernung eines Augenstieles ruft außerdem eine vorübergehende Zunahme des Putzens der Antennula auf der operierten Seite hervor. In 16 Tagen klingt dieser Effekt ab.

3. Einseitige Entfernung des Augenstieles stört die spontanen oder durch mechanische Reize ausgelösten Bewegungen der Antennula nicht. 
4. Während bei den meisten Langusten in Regeneraten der Antennulae (nach Amputation des distalen Segmentes und des Flagellum normale sensorische und motorische Funktionen vorhanden sind, sind bei etwa $1 / 3$ der Regenerate Abweichungen davon vorhanden, offenbar auf dem gelegentlichen Fehlen von nervösen Verbindungen beruhend.

5. Die Medulla terminalis im Augenstiel ist wahrscheinlich der für die normale Funktion der Antennula verantwortliche Teil des Nervensystems. Es bestehen Ähnlichkeiten in den Folgen der Augenstielentfernung bei Crustaceen und der Zerstörung der Corpora pedunculata bei Insekten.

We wish to express our appreciation to the staff of the Bermuda Biological Station for their hospitality and cooperation during the course of these experiments. Special thanks are due Messrs. Chester Burgess and Brunel Spurling for their assistance in the maintenance of the experimental animals. Dr. R. ALEXANDER kindly read and criticised the manuscript.

\section{References}

Bethe, A.: Studien über das Centralnervensystem von Carcinus maenas nebst Angaben über ein neues Verfahren der Methylenblaufixation. Arch. mikr. Anat. 44, 579-622 (1895).

- Das Nervensystem von Carcinus maenas. Ein anatomisch-physiologischer Versuch. I. und II. Arch. mikr. Anat. 50, 460-546, 589-639 (1897).

Burss, D. E.: Neuroendocrine control of locomotor activity in the land crab Gecarcinus lateralis. In: Neurosecretion. Memoirs of the Society for Endocrinology No 12 (H. Heller and R. B. ClaRk, ed.), pp. 391-410. New York: Academic Press 1962.

Cochran, D. M.: The skeletal musculature of the blue crab, Callinectes sapidus Rathbun. Smithson. Misc. Coll. 92, No 9 (1935).

HAnström, B.: The olfactory centers in crustaceans. J. comp. Neurol. 38, 221-250 (1925).

- Vergleichende Anatomie des Nervensystems der wirbellosen Tiere unter Berücksichtigung seiner Funktion, S. 1-628. Berlin: Springer 1928.

HELM, F.: Vergleichend-anatomische Untersuchungen über das Gehirn, insbesondere das „Antennalganglion" der Dekapoden. Z. Morph. u. Ökol. Tiere 12, $70-134(1928)$.

HerBst, C.: Über die Regeneration von antennenähnlichen Organen an Stelle von Augen. VII. Die Anatomie der Gehirnnerven und des Gehirnes bei Krebsen mit Antennulis an Stelle von Augen. Arch. Entwickl.-Mech. Org. 42, 407-489 (1916).

Holmes, S. J., and E. S. Homuth: The seat of smell in the crayfish. Biol. Bull. $18,155-160(1910)$.

Lindbera, R. G.: Growth, population dynamies, and field behavior in the spiny lobster, Panulirus interruptus Randall. Univ. Calif. Publ. Zool. 59, 157-248 (1955).

Lissmand, H. W., u. A. Wolskx: Funktion der an Stelle eines Auges regenerierten Antennule bei Potamobius leptodactylus Eschн. Z. vergl. Physiol. 19, 555-573 (1933).

MaYNaRD, D. M.: Organization of Neuropil. Amer. Zool. 2, 79_96 (1962). 
Schмтот, W.: Die Muskulatur von Astacus fluviatilis (Potamobius astacus L.). Ein Beitrag zur Morphologie der Decapoden. Z. wiss. Zool. 113, 165-251 (1915).

Sснӧле, H.: Complex Behavior. Ch. 13 in: The physiology of Crustacea, vol. II (T. H. Waterman, ed.), pp. 465-520. New York: Academic Press 1961.

SCUDAMORE, H. H.: The influence of the sinus glands upon molting and associated changes in the crayfish. Physiol. Zool. 20, 187-208 (1947).

Travis, D. F.: The molting cycle of the spiny lobster, Panulirus argus Latreili.E. I. Molting and growth in laboratory-maintained individuals. Biol. Bull. 107, $433-450$ (1954).

VTaLLANm, M. H.: Études histologiques et organologiques sur les centres nerveux et les organes des sens des animaux articulés. I. Le ganglion optique de la langouste (Palinurus vulgaris). Ann. Sci. Nat. Zool., Ser. VI 17, art. 3, 1-74 (1884).

Études histologiques et organologiques sur les centres nerveux et les organes des sens des animaux articulés. VI. Ann. Sei. Nat. Zool., Ser. VII 14, 405-456 (1893).

Vowles, D. M. : The function of the corpora pedunculata in bees and ants. Brit. J. Anim. Behav. 2, 116 (1954).

Wrersma, C. A. G.: Personnal communication 1962.

Dr. Donald M. Maynard,

The University of Michigan, Department of Zoology, Ann Arbor, Michigan, U. S. A. 